\title{
Trace Elements, Heavy Metals and Vitamin Levels in Patients with Coronary Artery Disease
}

\author{
Aysegul Cebi ${ }^{1 凶}$, Yuksel Kaya², Hasan Gungor ${ }^{3}$, Halit Demir $^{4}$, Ibrahim Hakki Yoruk ${ }^{4}$, Nihat Soylemez $^{2}$, \\ Yilmaz Gunes ${ }^{5}$, Mustafa Tuncer ${ }^{5}$
}

1. Giresun University Faculty of Health Sciences, Giresun, Turkey

2. Yuksek Ihtisas Training and Research Hospital, Department of Cardiology, Van, Turkey

3. Mus State Hospital, Department of Cardiology, Mus, Turkey

4. Yuzuncu Yil University Faculty of Science, Department of Chemistry, Van, Turkey

5. Yuzuncu Yil University, Faculty of Medicine, Department of Cardiology, Van, Turkey

Corresponding author: Aysegul Cebi, PhD, Giresun University Faculty of Health Sciences, Piraziz/Giresun, Turkey. Tel: +90.454.3613788, Fax: +90.454.3613544, e-mail: cebiaysegul@hotmail.com

(C) Ivyspring International Publisher. This is an open-access article distributed under the terms of the Creative Commons License (http://creativecommons.org/ licenses/by-nc-nd/3.0/). Reproduction is permitted for personal, noncommercial use, provided that the article is in whole, unmodified, and properly cited.

Received: 2011.05.12; Accepted: 2011.07.25; Published: 2011.08.02

\begin{abstract}
Aim: In the present study, we aimed to assess serum concentrations of zinc (Zn), copper $(\mathrm{Cu})$, iron $(\mathrm{Fe})$, cadmium $(\mathrm{Cd})$, lead $(\mathrm{Pb})$, manganese $(\mathrm{Mn})$, vitamins A (retinol), D (cholecalciferol) and $\mathrm{E}$ (a-tocopherol) in patients with coronary artery disease (CAD) and to compare with healthy controls.

Methods: A total of 30 CAD patients and 20 healthy subjects were included in this study. Atomic absorption spectrophotometry (UNICAM-929) was used to measure heavy metal and trace element concentrations. Serum a-tocopherol, retinol and cholecalciferol were measured simultaneously by high performance liquid chromatography (HPLC).

Results: Demographic and baseline clinical characteristics were not statistically different between the groups. Serum concentrations of retinol $(0.3521 \pm 0.1319$ vs. $0.4313 \pm 0.0465$ $\mathrm{mmol} / \mathrm{I}, \mathrm{p}=0.013)$, tocopherol $(3.8630 \pm 1.3117$ vs. $6.9124 \pm 1.0577 \mathrm{mmol} / \mathrm{I}, \mathrm{p}<0.001)$, cholecalciferol $(0.0209 \pm 0.0089$ vs. $0.0304 \pm 0.0059 \mathrm{mmol} / \mathrm{I}, \mathrm{p}<0.001)$ and $\mathrm{Fe}(0.5664 \pm 0.2360$ vs. $1.0689 \pm 0,4452 \mu \mathrm{g} / \mathrm{dI}, \mathrm{p}<0.001)$ were significantly lower in CAD patients. In addition, while not statistically significant serum $\mathrm{Cu}(1.0164 \pm 0.2672$ vs. $1.1934 \pm 0.4164 \mu \mathrm{g} / \mathrm{dI}$, $\mathrm{p}=0.073$ ) concentrations were tended to be lower in patients with $C A D$, whereas serum lead $(0.1449 \pm 0.0886$ vs. $0.1019 \pm 0.0644 \mu \mathrm{g} / \mathrm{dI}, \mathrm{p}=0.069)$ concentrations tended to be higher.

Conclusions: Serum level of trace elements and vitamins may be changed in patients with CAD. In this relatively small study we found that serum levels of retinol, tocopherol, cholecalciferol, iron and copper may be lower whereas serum lead concentrations may be increased in patients with CAD.
\end{abstract}

Key words: coronary artery disease; trace element; heavy metal; vitamin

\section{INTRODUCTION}

Coronary artery disease (CAD) is a leading cause of morbidity and mortality in developed countries and is emerging as an epidemic in developing countries (1). Traditional risk factors such as serum cho- lesterol, blood pressure and smoking account for not more than $50 \%$ of CAD mortality (2). There is strong evidence that oxidative free radicals have a role in the development of degenerative diseases including CAD 
(3). Oxidative free radicals increase the peroxidation of low density lipoprotein (LDL) thereby increasing its uptake by macrophages with increased foam cell formation and atherosclerosis, though other mechanisms may exist (4). Each antioxidant has different and important mechanisms of action since oxidative damage can be caused by lipid- or water-soluble molecules. Lipid-soluble antioxidants are likely to be very important in preventing the peroxidation of LDL and this action could be paramount in the prevention of atherosclerosis. As lypophilic molecules, vitamin E and beta-carotene are incorporated into the LDL particle. Vitamin E plays an essential protective role against free radical damage (5). Previous experimental and epidemiologic evidence suggested that some antioxidant vitamins appear to be important in reducing the risk of CAD (6).

Studies on the roles of trace elements in health and disease over the past 50 years have led to a good understanding of their mode of action and why they are essential to life (7). Some studies have assessed the association between iron status and CAD risk but the results have been inconsistent $(8,9)$.

The aim of the present study was to investigate the changes occurring in the serum level zinc $(\mathrm{Zn})$, copper $(\mathrm{Cu})$, iron $(\mathrm{Fe})$, cadmium $(\mathrm{Cd})$, lead $(\mathrm{Pb})$, manganese $(\mathrm{Mn})$, vitamins A (retinol), D (cholecalciferol) and $\mathrm{E}$ (a-tocopherol) in patients with CAD.

\section{MATERIALS AND METHODS}

The study population included 30 patients having angiographically demonstrated CAD and 20 patients having normal coronary arteries attending cardiology clinic at Yuzuncu Yil University Hospital. The study was approved by the local ethics committee according to the declaration of Helsinki, and patients gave written informed consent.

\section{Sample Collection And Analysis}

Blood samples were collected into tubes without coagulant. Serum was obtained by centrifugation at $2500 \mathrm{rpm}$ for 15 minutes and stored at $-80^{\circ} \mathrm{C}$ until assayed. Serum a-tocopherol, retinol and cholecalciferol were measured simultaneously by high performance liquid chromatography (HPLC) (10-12). Serum concentrations of $\mathrm{Zn}, \mathrm{Cu}, \mathrm{Fe}, \mathrm{Cd}, \mathrm{Pb}$ and $\mathrm{Mn}$ were determined by Atomic Adsorption Spectrophotometer.

\section{Statistical Analysis}

Data were presented as mean \pm standard deviation (SD). Using SPSS package 16.0 (SPSS Inc. Chicago, IL, USA), data between the groups were compared with Student's $t$ test for continuous variables and chi-square t-test for continuous variables. Mann-Whitney's U-test was used for variables without normal distribution. A two-tailed P-value of $<0.05$ was considered significant.

\section{RESULTS AND DISCUSSION}

Clinical characteristics and serum cholesterol levels were not significantly different in patients with and without CAD (Table 1). Comparisons of the levels of the vitamins (retinol, tocopherol and cholecalcifer$\mathrm{ol})$, and trace elements and heavy metals $(\mathrm{Zn}, \mathrm{Cu}, \mathrm{Fe}$, $\mathrm{Cd}, \mathrm{Pb}$ and $\mathrm{Mn}$ ) in patients with $\mathrm{CAD}$ and the control group are shown in Table 2. Compared with the control group, serum concentrations of retinol, tocopher$\mathrm{ol}$, cholecalciferol and iron were significantly lower in patients with CAD.

Table 1: Clinical characteristics of study population.

\begin{tabular}{llll}
\hline & $\begin{array}{l}\text { Patients with CAD } \\
(\mathrm{n}=30)\end{array}$ & $\begin{array}{l}\text { Control group } \\
(\mathrm{n}=20)\end{array}$ & P-value \\
\hline Age $($ years) & $59.1 \pm 10.6$ & $57.5 \pm 9.9$ & 0.613 \\
BMI $\left(\mathrm{kg} / \mathrm{m}^{2}\right)$ & $29.0396 \pm 4.0172$ & $27.9001 \pm 3.5504$ & 0.309 \\
Smoking $(\%)$ & $19(\% 63.3)$ & $11(\% 55)$ & 0.383 \\
Hypertension $(\%)$ & $19(\% 63.3)$ & $7(\% 35.0)$ & 0.082 \\
Diabetes mellitus $(\%)$ & $13(\% 43.3)$ & $5(\% 25.0)$ & 0.237 \\
Total cholesterole $(\mathrm{mg} / \mathrm{dl})$ & $184.5 \pm 40.2$ & $203.7 \pm 37.8$ & 0.120 \\
Triglyceride $(\mathrm{mg} / \mathrm{dl})$ & $200.8 \pm 96.4$ & $177.8 \pm 52.8$ & 0.572 \\
LDL cholesterol $(\mathrm{mg} / \mathrm{dl})$ & $120.5 \pm 20.8$ & $133.0 \pm 28.6$ & 0.178 \\
HDL cholesterol $(\mathrm{mg} / \mathrm{dl})$ & $39.4 \pm 7.5$ & $42.7 \pm 10.0$ & 0.331 \\
Creatinine $(\mathrm{mg} / \mathrm{dl})$ & $0.85 \pm 0.17$ & $0.87 \pm 0.21$ & 0.849 \\
\hline
\end{tabular}

BMI: body mass index, HDL: High Density Lipoprotein, LDL: Low Density Lipoprotein

Data is presented as mean \pm SD. 
Table 2: Serum levels of vitamins and trace elements in study population.

\begin{tabular}{llll}
\hline & $\begin{array}{l}\text { Patients with CAD } \\
(\mathrm{n}=30)\end{array}$ & $\begin{array}{l}\text { Control group } \\
(\mathrm{n}=20)\end{array}$ & P value \\
\hline Retinol $(\mathrm{mmol} / \mathrm{I})$ & $0.3521 \pm 0.1319$ & $0.4313 \pm 0.0465$ & 0.013 \\
Tocopherol $(\mathrm{mmol} / \mathrm{I})$ & $3.8630 \pm 1.3117$ & $6.9124 \pm 1.0577$ & $<0.001$ \\
Cholecalciferol $(\mathrm{mmol} / \mathrm{I})$ & $0.0209 \pm 0.0089$ & $0.0304 \pm 0.0059$ & $<0.001$ \\
$\mathrm{Fe}(\mu \mathrm{g} / \mathrm{dI})$ & $0.5664 \pm 0.2360$ & $1.0689 \pm 0,4452$ & $<0.001$ \\
$\mathrm{Mn}(\mu \mathrm{g} / \mathrm{dI})$ & $0.0606 \pm 0.0558$ & $0.0429 \pm 0.0638$ & 0.304 \\
$\mathrm{~Pb}(\mu \mathrm{g} / \mathrm{dI})$ & $0.1449 \pm 0.0886$ & $0.1019 \pm 0.0644$ & 0.069 \\
$\mathrm{Cu}(\mu \mathrm{g} / \mathrm{dI})$ & $1.0164 \pm 0.2672$ & $1.1934 \pm 0.4164$ & 0.073 \\
$\mathrm{Cd}(\mu \mathrm{g} / \mathrm{dI})$ & $0.0070 \pm 0.0046$ & $0.0087 \pm 0.0060$ & 0.282 \\
$\mathrm{Zn}(\mu \mathrm{g} / \mathrm{dI})$ & $0.8514 \pm 0.5522$ & $0.9087 \pm 0.1833$ & 0.657 \\
\hline
\end{tabular}

$\mathrm{Cd}$ : cadmium , Cu: copper, Fe: iron, Mn:manganese, $\mathrm{Pb}$ : lead, $\mathrm{Zn}$ : zinc

Data is presented as mean $\pm \mathrm{SD}$.

In this study, we found that serum concentrations of retinol, tocopherol, cholecalciferol and Fe were significantly decreased in patients with CAD. In addition, while not statistically significant, serum $\mathrm{Cu}$ concentrations tended to be lower in patients with $\mathrm{CAD}$, whereas serum Fe concentrations tended to be higher.

CAD has been associated with several risk factors including family history, age, elevated blood cholesterol, diabetes mellitus, cigarette smoking and hypertension (13). Several trace elements have also been implicated in the pathogenesis of CAD (14). Low serum $\mathrm{Zn}$ levels have been associated with increased cardiovascular mortality (14). The results of the present study show that serum $\mathrm{Zn}$ concentrations were significantly lower in the control group. Lower $\mathrm{Zn}$ levels in CAD may be a cause or a result of another unknown parameter. Lukaski et al. (1988) observed a slight increase in serum $\mathrm{Cu}$ and a signficant increase in urine $\mathrm{Cu}$ levels in patients suffering from myocardial infarction (MI) (15). Reunanen et al. (1996) found increased levels of serum $\mathrm{Cu}$ in patients with $\mathrm{CAD}$ (14). In contrast, in our study, the serum $\mathrm{Cu}$ concentrations tended to be lower in patients with CAD.

Epidemiological investigations that associate body Fe stores with CAD risk have produced conflicting results; these may in part be explained by the use of nonspesific measures of body Fe stores, such as serum transferrin (16-19). The strongest supporting evidence that $\mathrm{Fe}$ is a risk factor for CAD stems from a cohort study of eastern Finnish men, in which high levels of serum ferritin and dietary Fe intake were positively associated with the incidence of myocardial infarction. Ascherio et al. (1994) reported an increased risk of nonfatal MI or fatal CAD with Fe intake (17). Sullivan et al. (1981) proposed that depletion of body Fe stores reduced the risk of CAD (16). Most subsequent prospective studies investigating whether $\mathrm{Fe}$ status or dietary Fe intake is associated with an increased risk of MI or CAD have not supported the hypothesis that high body Fe stores increase the risk of CAD $(20,21,18)$. Accordingly, we found significantly lower serum iron levels in patients with CAD.

Because of its possible role in preventing heart disease researchers have taken interest in fat-soluble tocopherol. Recent studies have suggested that a-tocopherol supplementation can help reduce the incidence of coronary disease $(1,22)$. However, a large prospective study found no benefit of tocopherol supplemantation in preventing CAD. Levels of tocopherol were reported to be decreased in coronary artery disease (23). Our results also demonstrate that serum tocopherol levels were lower in CAD patients compared to controls.

As far as we know, there is no study examining serum $\mathrm{Cd}$ levels in CAD in the literature. We have found that serum $\mathrm{Cd}$ levels were significantly decreased in CAD. Therefore, the significance of this finding should be further analysed in larger studies.

$\mathrm{Mn}$ is an element essential for health in trace amounts, but toxic at higher levels. There are a few reports in the literature examining the effects of excess oral exposure of humans to $\mathrm{Mn}$. The urine of CAD patients also shows higher Mn concentrations than that of healthy controls (24). In atherosclerotic subjects, the Mn content of the heart and aorta of atherosclerotic subjects is lower and plasma levels are higher than in healthy controls (25-27). This increase is so rapid and specific that it may be used as a diagnostic indicator of a recent MI. In the present study however, Mn concentrations were not significantly increased in patients with CAD.

Blood $\mathrm{Pb}$ level was not found to be associated with coronary heart disease incidence (28). The cardiovascular effects of $\mathrm{Pb}$ have been associated with increased blood pressure and hypertension. Studies in 
general populations have identified a positive association of $\mathrm{Pb}$ exposure with clinical cardiovascular, $\mathrm{CAD}$ and stroke mortality; and peripheral arterial disease, but the number of studies is small $(29,30)$. Numerous experimental studies in animals have shown irrefutable evidence that chronic exposure to low $\mathrm{Pb}$ levels results in arterial hypertension that persists long after the cessation of $\mathrm{Pb}$ exposure (29). We couldn't found information about $\mathrm{Pb}$ levels among patients with CAD having no history of $\mathrm{Pb}$ exposure in literature. In the present study, it was found that mean levels of serum $\mathrm{Pb}$ tended to be higher in CAD patients.

We found that mean values for retinol were significantly lower in patients with CAD compared to the control group. Other investigators have also reported decreased retinol levels in patients with CAD $(31,32)$. In other studies, Levels of retinol were similar in patients with CAD compared to controls $(5,6,31,32)$. Numerous studies have explored whether retinol supplements can help to prevent cardiovascular diseases. Results of large randomized controlled trials of the impact of antioxidant vitamin supplements have been ambiguous or contradictory (33). The current evidence does not support indiscriminate use of retinol to prevent or to reduce CAD $(4,33)$.

Similar to results reported in previous studies, we found serum cholecalciferol levels to be lower in CAD. Cholecalciferol deficiency is associated with increased cardiovascular risk, above and beyond established cardiovascular risk factors $(34,35)$. Several mechanisms may explain the link between cholecalciferol deficiency and cardiovascular disease. Clinical studies have reported cross-sectional associations between lower cholecalciferol levels and plasma renin activity, blood pressure, coronary artery calcification and prevalent cardiovascular disease (36-41).

In conclusion, serum levels of trace elements and vitamins may be changed in patients with CAD. The higher or lower levels may be both a cause and effect of atherosclerosis or the result of another unknown parameter. In this relatively small study we found that serum levels of retinol, tocopherol, cholecalcifer$\mathrm{ol}, \mathrm{Fe}$ and $\mathrm{Cu}$ may be lower whereas serum $\mathrm{Pb}$ concentrations may be increased in patients with CAD. These findings need to be further investigated in larger well designed studies.

\section{Conflict of Interest}

The authors have declared that no conflict of interest exists.

\section{References}

1. Yusoff K. Vitamin E in cardiovascular disease: Has the diet been cast? Asia Pac J Clin Nutr. 2002; 11: 443-447.

2. Gey KF, Puska J, Jordon P, et al. Inverse correlation between plasma vitamin $\mathrm{E}$ and mortality from ischemic heart disease in cross-cultural epidemiology. Am J Clin Nutr. 1991; 53: 326-334.

3. Ames BN, Shigenaga MK, Hagen TM. Oxidants, antioxidants, and the degenerative diseases of aging. Proc Natl Acad Sci. 1993; 90: 7915-7922.

4. Steinberg D. Anti-oxidant vitamins and coronary heart disease. N Engl J Med. 1993; 328: 1487-1489.

5. Marchioli R. Antioxidant vitamins and prevention of cardiovascular disease: laboratory, epidemiological and clinical trial data. Pharmacol Res. 1999; 40: 227-238.

6. Adams AK, Wermuth EO, Mcbride PE. Antioxidant vitamins and the prevention of coronary heart disease. Am Fam Physician. 1999; 60: 895-904

7. Yavuz B, Ertugrul DT, Cil H, et al. Increased Levels of $25 \mathrm{Hy}-$ droxyvitamin D and 1,25-Dihydroxyvitamin D After Rosuvastatin Treatment: A Novel Pleiotropic Effect of Statins? Cardiovasc Drugs Ther. 2009; 20: 312-320.

8. Tuomainen TP, Punnonen K, Nyyssonen K, et al. Association between body iron stores and the risk of acute myocardial infarction in men. Circulation. 1998; 97: 1461-1466.

9. Danesh J, Appleby P. Coronary heart disease and iron status: meta-analyses of prospective studies. Circulation. 1999; 99: 852-854.

10. Miller KW and Yang CS. An Isocratic High-Performance Liquid Chromatography Method for the Simultaneous Analysis of Plasma Retinol, a-tocopherol and Various Carotenoids. Anal Biochem. 1985; 145: 21-26.

11. Zaspel BJ, and Csallany S. Determination of Alpha-Tocopherol in Tissues and Plasma by High-Performance Liquid Chromatography. Anal Biochem. 1983; 130: 146-150.

12. Reynolds SL and Judd HJ. Rapid Procedure for the Determination of Vitamins A and D in Fortified Skimmed Milk Powder Using High-Performance Liquid Chromatography. Anal Biochem. 1984; 109: 489-492.

13. Kagan A, Kannel WB, Dawber TR, et al. The coronary profile. Ann Ny Acad Sci. 1963; 97: 883-894.

14. Reunanen A, Knekt P, Marniemi J, et al. Serum calcium, magnesium, copper and zinc and risk of cardiovascular death. Eur J Clin Nutr. 1996; 50: 431-437.

15. Lukaski HC, Klevay LM, Milne DB. Effects of dietary copper on human autonomic cardiovascular function. Eur J Appl Physiol. 1988; 58: 74-80.

16. Sullivan JL. Iron and the sex difference in heart disease risk. Lancet. 1981; 1: 1293-1294.

17. Ascherio A, Willett WC, Rimm EB, et al. Dietary iron intake and risk of coronary disease among men. Circulation. 1994; 89: 969-974.

18. Sempos CT, Looker AC, Gillum RF, et al. Body iron stores and the risk of coronary heart disease. N Engl J Med. 1994; 330: 1119-1124.

19. Ascherio A, Willett WC, Rimm EB, et al. Blood donations and risk of coronary heart disease in men. Circulation. 2001;103: 52-57.

20. Reunanen A, Takkunen $\mathrm{H}$, Knekt $\mathrm{P}$, et al. Body iron stores, dietary iron intake and coronary heart disease mortality. J Intern Med. 1995; 238: 223-230.

21. Liao Y, Cooper RS, McGee DL. Iron status and coronary heart disease: negative findings from the NHANES I epidemiologic follow-up study. Am J Epidemiol. 1994; 139: 704-712.

22. Rimm EB, Stampfer MJ, Ascherio A, et al. Vitamin E consumption and the risk of coronary heart disease in men. $\mathrm{N}$ Engl J Med. 1993; 328: 1450-1456. 
23. Lonn E, Bosch J, Yusuf S, et al. Effects of long-term vitamin E supplementation on cardiovascular events and cancer: a randomized controlled trial. JAMA. 2005; 293:1338-47.

24. Kanabrocki EL, Scheving LE, Olwin JH, et al. Circadian variation in the urinary excretion of electrolytes and trace elements in men. Am J Anat. 1983; 166: 121-148.

25. Volkov NF. The cobalt, manganese and zinc content in the blood and internal organs of atherosclerotic patients. Ter Arkh. 1962; 34: 52-56.

26. Bala IuM, Plotko SA, Furmenko G. Content of manganese, nickel, zinc, copper, silver and lead in the blood, aorta, liver, kidneys and pancreas of atherosclerotic patients. Ter Arkh. 1967; 39: 105-111.

27. Masironi R. Trace elements and cardiovascular diseases. Bull World Health Organ. 1969; 40: 305-312.

28. Kromhout D. Blood lead and coronary heart disease risk among elderly men in Zutphen the Netherlands. Environ Health Perspect. 1988; 78: 43-46.

29. Navas-Acien A, Guallar E, Silbergeld EL, et al. Lead Exposure and Cardiovascular Disease-A Systematic Review. Environ Health Perspect. 2007; 115: 472-482.

30. Lustberg M, Silbergeld E. Blood lead levels and mortality. Arch Intern Med. 2002; 162: 2443-2449.

31. Rock E, Winklhofer-Roob BM, Ribalta J, et al. Vitamin A, vitamin $\mathrm{E}$ and carotenoid status and metabolism during ageing: functional and nutritional consequences (VITAGE PROJECT). Nutr Metab Cardiovasc Dis. 2001; 11: 70-73.

32. Omenn GS, Goodman GE, Thornquist MD, et al. Effects of acombination of $\beta$-carotene and vitamin $A$ on lung cancer and cardiovascular disease. NEJM. 1996; 334: 1150-1155.

33. Riccioni G, Bucciarelli T, Mancini B, et al. Antioxidant Vitamin Supplementation in Cardiovascular Diseases. Ann Cli Lab Sci. 2007; 37: 12-16.

34. Malabanan A, Veronikis IE, Holick MF. Redefining vitamin D insufficiency. Lancet. 1998; 351: 805-806.

35. Wang TJ, Pencina MJ, Booth SL, et al. Vitamin D Deficiency and Risk of Cardiovascular Disease. Circulation. 2008; 117: 503-511.

36. Carrie W, Nemerovski PD, Michael P, et al. Vitamin D and Cardiovascular Disease. Pharmacotherapy. 2009; 29: 691-708.

37. Lind L, Hanni A, Lithell $\mathrm{H}$, et al. Vitamin D is related to blood pressure and other cardiovascular risk factors in middle-aged men. Am J Hypertens. 1995; 8: 894-901.

38. Watson KE, Abrolat ML, Malone LL, et al. Active serum vitamin D levels are inversely correlated with coronary calcification. Circulation. 1997; 96: 1755-1760.

39. Doherty TM, Tang W, Dascalos S, et al. Ethnic origin and serum levels of 1,25-dihydroxyvitamin D3 are independent predictors of coronary calcium mass measured by electron-beam computed tomography. Circulation. 1997; 96: 1477-1481.

40. Scragg R, Jackson R, Holdaway IM, et al. Myocardial infarction is inversely associated with plasma 25 -hydroxyvitamin D3 levels: a community-based study. Int J Epidemiol. 1990; 19: 559-563.

41. Zittermann A, Schleithoff SS, Tenderich G, et al. Low vitamin D status: a contributing factor in the pathogenesis of congestive heart failure. J Am Coll Cardiol. 2003; 41: 105-112. 